\title{
Aeromonas sobria
}

National Cancer Institute

\section{Source}

National Cancer Institute. Aeromonas sobria. NCI Thesaurus. Code C86130.

A species of facultatively anaerobic, Gram negative, rod shaped bacteria assigned to the phylum Proteobacteria. This bacteria is motile by polar flag ella, oxidase positive and hemolytic. A. sobria is found in soil and water and is pathogenic, causing gastroenteritis, bacteremia, and soft tissue infections, especially of the eye. 